\title{
HEPARIN BINDING ANALYSIS OF BOAR SPERM AND ITS RELATION WITH FARROWING CAPACITY
}

\author{
Dora DAPINO ${ }^{1}$, Juan TeIJEIRO ${ }^{2}$, Fernando CANE $^{3}$ and Patricia E. MARINI ${ }^{2 *}$ \\ ${ }^{1}$ Cátedra de Fisiología, Facultad de Ciencias Veterinarias, Universidad Nacional de \\ Rosario, Rosario, Argentina; ${ }^{2}$ Área Biología, Facultad de Ciencias Bioquímicas y \\ Farmacéuticas, Universidad Nacional de Rosario and IBR-CONICET, Suipacha 590, \\ S2002LRK Rosario, Argentina; ${ }^{3}$ Instituto de Porcinotecnia, Ministerio de Producción, \\ Provincia de Santa Fe, Argentina
}

(Received 16 July 2012; accepted 11 December 2012)

\begin{abstract}
New methods for the evaluation of semen quality according to in vivo reproductive data are useful tools for identifying boars of lower fertility among individuals with standard semen parameters. In this study, indirect fluorescence microscopy was used to evaluate the heparin binding site distribution upon capacitation of sperm from eight boars arbitrarily distributed into Groups I and II according to differential farrowing rates (Group I: $\geq 70 \%$, Group II: $<70 \%$ ). Additionally, the ability of sperm to bind to solubilised zona pellucida (ZP) was assayed in the presence or absence of heparin. Samples of two individuals of Group II showed lower percentage of $\mathrm{B}$ pattern in relation to other individuals $(\mathrm{P}<0.001)$. The number of spermatozoa attached to ZP after $2 \mathrm{~h}$ of incubation in capacitating conditions with heparin was significantly lower than in its absence $(\mathrm{P}<0.0001)$. These results suggest that heparin binding site distribution concerning capacitation may be indicative of the availability of proteins involved in the fertilisation process, specifically at the initial sperm-oocyte recognition. Differences in heparin binding site dynamics during capacitation may help identify a subpopulation of individuals with lower fertilising capacity and normal spermiogram, which is particularly useful at high-production establishments.
\end{abstract}

Key words: Boar sperm, farrowing rate, capacitation, heparin, sulphated glycosaminoglycans

Currently, there are many methods for semen evaluation. However, the failure to find strong correlations between them and fertility in vivo remains (Broekhuijse et al., 2012). Works in cattle have focused the evaluation of semen quality on the measurement of possible indicators of fertility, such as the presence of some of the seminal plasma proteins or heparin-binding proteins (HBP) (Bellin et al., 1996). In this species, HBP have been identified as being capable of

*Corresponding author; E-mail: pmarini@fbioyf.unr.edu.ar; Phone: 0054 (341) 435-0661/ ext. 122; Fax: 0054 (341) 480-4601 
influencing the fertilising ability of sperm, and different levels of fertility have been found according to HBP concentration in sperm (Bellin et al., 1996; RodríguezMartínez et al., 2011). However, the possible role of this type of proteins as indicators of fertility in pig has not yet been examined.

In swine, spermadhesins are the main components of the seminal plasma. This group consists of five proteins with their variants, which are classified according to their amino terminal sequence and biological activity as AWN-1 and 2, AQN-1, 2 and 3, DQH, PSP-I and PSP-II. Of them, AQN-1, AQN-3, AWN-1, AWN-2 and DQH belong to the group of proteins that bind to heparin (Sanz et al., 1993). The HBP have been described as molecules associated with the surface of boar sperm, which bind to the latter by interaction with glycoproteins and lipids of the plasma membrane (Jonáková et al., 2007; Rodríguez-Martínez et al., 2011).

Mammalian spermatozoa reach the ability to fertilise the oocyte only after they complete a complex series of physical-chemical modifications called capacitation. It is well known that, in pigs, some spermadhesins are removed from the surface of sperm during capacitation while some HBP, as DQH, remain adsorbed to sperm and interact with components of the zona pellucida (ZP) at fertilisation (Monásková et al., 2007; Töpfer-Petersen et al., 2008). Also, strong evidence indicates that capacitation involves a redesign of the lipid architecture of the sperm plasma membrane (Van Gestel et al., 2007; Leahy and Gadella, $2011 a, b$ ), with the consequent redistribution of proteins on the surface (Gadella et al., 2008). Previously, the topology and dynamics of heparin binding to boar sperm have been evaluated by indirect fluorescence microscopy. Sperm incubated with biotinylated heparin showed differential heparin binding at different physiological stages (Dapino et al., 2009). Two different fluorescent patterns (A and B) were found. In pattern A, probably corresponding to non-capacitated sperm, fluorescence located mostly to the postacrosomal region; and in pattern $\mathrm{B}$, corresponding to $50-60 \%$ of sperm incubated under capacitating conditions, fluorescence located to the acrosomal region.

The previous observations lead us to hypothesise that heparin-binding sites redistribution may be related to sperm-ZP interaction, and thus to fertility rates. The objectives of this work were to determine if possible differences in the dynamics of heparin-binding site distribution on sperm cells correlate to different degrees of fertility measured in vivo as farrowing rate, and to analyse the role of heparin in the process of interaction between sperm and the ZP in swine.

\section{Materials and methods}

\section{Reagents and media}

Except when indicated, the reagents used were from Sigma-Aldrich, Argentina. Sperm capacitating medium, Tyrode's medium, TALP (Parrish et al., 
1988) contains $96 \mathrm{mM} \mathrm{NaCl}, 3.1 \mathrm{mM} \mathrm{KCl}, 2.0 \mathrm{mM} \mathrm{CaCl}_{2}, 0.4 \mathrm{mM} \mathrm{MgSO}_{4}$, $0.3 \mathrm{mM} \mathrm{NaH}_{2} \mathrm{PO}_{4}, 20 \mathrm{mM}$ HEPES, $21.6 \mathrm{mM}$ sodium lactate, $1 \mathrm{mM}$ sodium pyruvate, $15 \mathrm{mM} \mathrm{NaHCO}$ and $3 \mathrm{mg} / \mathrm{ml} \mathrm{BSA}$.

\section{Semen collection}

Semen was collected from adult fertile crossbred boars [Pietrain $\times$ Large White $\times$ Duroc] by the glove-hand method. Sperm-rich fraction was diluted in Sperm plus L.C. ${ }^{\circledR}$ (Laboratorio Productos Agropecuarios, I. Sobrino S.L., San Juan de Mozarripar, Zaragoza, Spain) and conserved at $16{ }^{\circ} \mathrm{C}$ until use (not more than $24 \mathrm{~h}$ from collection).

\section{Evaluation of semen quality}

Samples were tested through standard assessment of seminal quality: motility, vitality, concentration, morphology and hypoosmotic swelling test (HOST). All the samples conformed to normal seminal parameters for the pig (Vázquez et al., 1997), such as motility $>70 \%$, vitality $>70 \%$, total sperm in the ejaculate $>20 \times 10^{9}$, morphological defects $<15 \%$ and HOST $50-70 \%$.

\section{Sperm capacitation}

Motile sperm were selected by centrifugation at $50 \times g$ for $10 \mathrm{~min}$ at $16^{\circ} \mathrm{C}$. The supernatant was centrifuged at $700 \times g$ for 5 min for sperm recovery. The pellet was resuspended to $10^{7} \mathrm{sperm} / \mathrm{ml}$ in TALP medium and incubated at $37^{\circ} \mathrm{C}$ for 60 and $120 \mathrm{~min}$. The occurrence of capacitation was determined by the ability to undergo acrosome reaction (AR) in the presence of calcium ionophore A23187 (Tardif et al., 1999). Acrosomal reaction was visualised by Wells-Awa staining (Wells and Awa, 1970) and the viability was analysed by eosin-nigrosin staining method at the end of the incubation period.

\section{Distribution of boars into groups according to their fertility rates}

Boars and sows used for this work were located at the same farm in Chañar Ladeado, Santa Fe, Argentina. Eight boars were used according to the following common characteristics: (a) to submit a normal spermiogram with regard to the normal parameters for pigs, taking five evaluations per animal as a minimum; (b) the period of study was always equal to or greater than a year; (c) the animals were under the same environmental conditions; (d) the number of inseminated females was always equal to or greater than 100 per each boar.

Fertility was estimated as farrowing rate, calculated for each boar as the number of females that farrowed after artificial insemination (Clark et al., 1989) on the basis of records provided by the farm from 3,722 inseminated sows, and according to the formula: farrowed sows/inseminated sows. From the obtained 
values, two groups of animals were arbitrarily formed: Group I: fertility or farrowing rate $\geq 70 \%$; Group II: fertility or farrowing rate $<70 \%$.

\section{Analysis of the dynamics of heparin binding to sperm}

Sperm from animals of Groups I and II (4 samples per animal) were assessed by indirect fluorescence using the technique of sperm incubation with biotinylated heparin, revealed with streptavidin-FITC (Dapino et al., 2009).

Aliquots of $10 \mu \mathrm{l}$ of sperm were taken at 0,60 and $120 \mathrm{~min}$ of incubation in capacitating media, smeared on slides and air dried. The slides were incubated in PBS containing $5 \%(\mathrm{p} / \mathrm{v}) \mathrm{BSA}$, for $2 \mathrm{~h}$ at $39^{\circ} \mathrm{C}$, followed by incubation with biotinylated heparin $(100 \mu \mathrm{g} / \mathrm{ml})$ in PBS/BSA. After washing with PBS/BSA, samples were incubated with $100 \mu \mathrm{g} / \mathrm{ml}$ streptavidin conjugated to FITC and washed with PBS/BSA buffer. Finally, $10 \mu \mathrm{l}$ of PBS:glycerol $(1: 9, \mathrm{v} / \mathrm{v})$ were added and the samples were observed simultaneously with phase contrast and fluorescence (Nikon E800, Microlat, Buenos Aires, Argentina).

\section{Zona pellucida binding assay}

Porcine ovaries were obtained from prepubertal gilts at a local slaughterhouse and stored at $-20{ }^{\circ} \mathrm{C}$ until use. Groups of 20 ovaries were placed in a Petri dish with PBS, pH 7.2, containing $2 \mathrm{mM}$ sodium citrate and $2 \mathrm{mM}$ EDTA. Oocytes were released from ovaries to the solution using a scalpel. After follicles from 200 ovaries were disrupted, the buffer containing the oocytes was filtered through 1500, 210, 152 and $70 \mu \mathrm{m}$ mesh nylon screen (Sigma, Aldrich) as previously described by Hedrick and Wardrip (1986). The oocytes collected in the $70 \mu \mathrm{m}$ screen were removed from it with $10 \mathrm{ml}$ of PBS, transferred to a Potter homogeniser and ruptured by passing the teflon rod 20 times. The zonae pellucidae were collected on a $40 \mu \mathrm{m}$ screen, extensively washed with distilled water, solubilised in $5 \mathrm{mM}$ ammonium bicarbonate, $\mathrm{pH} 8.2$, at $70{ }^{\circ} \mathrm{C}$ for $30 \mathrm{~min}$ and centrifuged at $10,000 \times \mathrm{g}$ for $10 \mathrm{~min}$ to remove particulate debris. After determining protein concentration (Lowry et al., 1951) $0.75 \mu \mathrm{g}$ of heat-solubilised ZP were spotted on coverslips and dried at $37^{\circ} \mathrm{C}$ on a warming plate. The ZP-coated coverslips were then inverted on top of $10 \mu \mathrm{l}$ of sperm suspension $\left(10^{7} / \mathrm{ml}\right)$ in capacitating medium and in the presence or absence of $10 \mu \mathrm{g} / \mathrm{ml}$ of heparin, and were incubated in humidified chamber for 15,30 or $60 \mathrm{~min}$ before exhaustive wash with PBS (Richardson et al., 1991). Coverslips without ZP were used as control and slides were scored under phase contrast microscope $(\times 40)$ counting 10 fields per each sample.

\section{Statistical analysis of the data}

The statistical analysis was performed using analysis of variance (ANOVA). When the results of the test (f) were significant for ANOVA, individual averages 
were also tested by the model of Tukey, verifying assumptions by means of analysis of residues.

\section{Results}

\section{Analysis of the topography of heparin binding}

Boars with semen quality parameters indistinguishable from the normal values for the porcine species were arbitrarily distributed into two groups (I and II) on the basis of differences in their farrowing rates. Group I was composed of individuals with a fertility rate greater than or equal to $70 \%$ and Group II of individuals with less than $70 \%$ fertility rate (the values for each boar are detailed in Table 1). The difference between farrowing rates for any two animals from different groups was greater than $10 \%$. Sperm samples from each boar were evaluated for distribution of heparin-binding sites upon capacitation by indirect fluorescence microscopy.

Table 1

Distribution of boars according to their farrowing rates

\begin{tabular}{lccc}
\hline Boar & Farrowed sows & Mated sows & Farrowing rate (\%) \\
\hline Group I & & & \\
1 & 598 & 748 & 79.9 \\
2 & 519 & 672 & 77.2 \\
3 & 489 & 620 & 78.9 \\
4 & 491 & 646 & 76.0 \\
\hline Group II & & & \\
5 & 289 & 456 & 63.4 \\
6 & 343 & 548 & 62.6 \\
7 & 81 & 123 & 65.9 \\
8 & 69 & 114 & 60.5 \\
\hline
\end{tabular}

Explanations: Farrowing rate was calculated for eight boars according to the formula: farrowed sows/inseminated sows and, from the obtained values, two groups of animals were arbitrarily formed: Group I: farrowing rate $\geq 70 \%$, Group II: farrowing rate $<70 \%$

We found significant differences in the percentage of sperm showing pattern B fluorescence in two animals (no. 6 and 8), within Group II (Fig. 1). These showed a significantly lower percentage of fluorescence in the acrosomal region at all incubation times tested $(\mathrm{P}<0.001)$ in relation to individuals of Group I and to the other two animals of Group II. The capacitation values assessed by the ability of sperm to undergo AR in the presence of calcium ionophore A23187 were consistent with the normal parameters (data not shown). The viability assessed by eosin-nigrosin staining was around $70 \%$ throughout the experiment. 


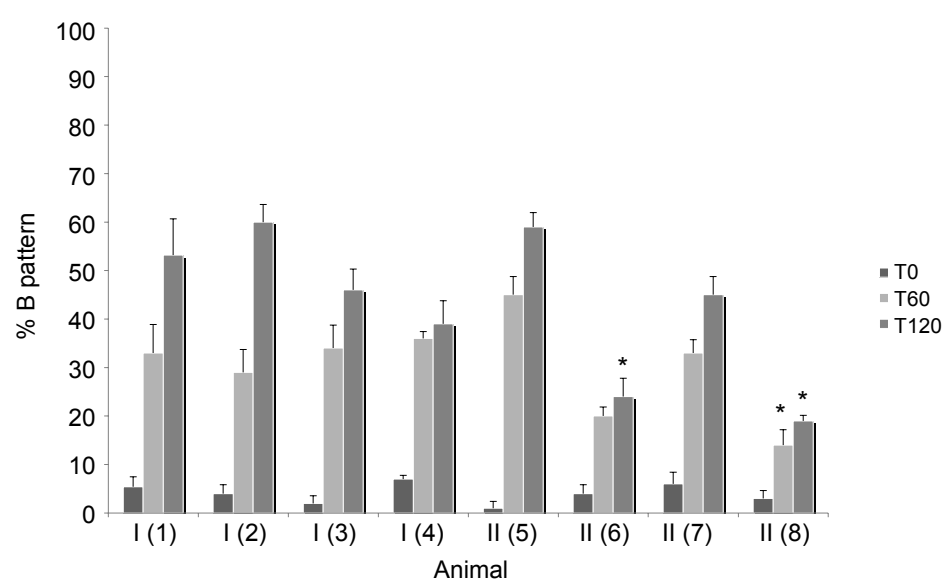

Fig. 1. Percentage of heparin-binding B pattern in sperm of breeding pigs with different fertility. Boars were classified as Groups I or II according to their farrowing rates, as detailed, and sperm samples were evaluated for biotinylated heparin-binding upon incubation under capacitating conditions using indirect fluorescence microscopy. Each value corresponds to the average of five replicates of heparin-binding (B) pattern detection at different incubation times, for each individual $(\mathrm{n}=8)$. The animals are named according to the group to which they belong and, between brackets, the number which identifies them. $\left({ }^{*}\right)$ indicates significant differences $(\mathrm{P}<0.001)$

Interestingly, no significant differences in litter size were noted between boars from Groups I and II (data not shown).

\section{Effect of heparin on in vitro sperm binding to zona pellucida}

Zona pellucida was obtained from pigs as described in the Materials and methods section, and the ability of sperm to bind to it was assayed in the presence or absence of heparin. When spermatozoa were incubated under capacitating conditions in the presence of heparin, the number of sperm that attached to $\mathrm{ZP}$ was significantly lower compared to those incubated in the absence of heparin after $30 \mathrm{~min}$. In addition, the differences increased after $60 \mathrm{~min}(\mathrm{P}<0.0001)$ (Table 2). In untreated coverslips, the number of attached sperm was minimal and did not vary significantly throughout the incubation process, regardless of the presence of heparin.

\section{Discussion}

Fertility differences among boars showing normal pre-established spermiogram parameters are difficult to detect, making the decreased fertilising ability undetectable until farrowing rates or other parameters used in farming programmes are analysed. Recently, boar- and semen-related parameters have been shown to explain only $4 \%$ of the variation in farrowing rates (Broekhuijse et al., 2012). Thus, other methods are needed to detect suboptimal in vivo fertilising ability. 
Table 2

Binding to zona pellucida (ZP) of sperm capacitated in the presence or absence of heparin, analysed by the coverslip method

\begin{tabular}{lrrrrr}
\hline \multirow{2}{*}{$\begin{array}{l}\text { Incubation } \\
\text { period }(\mathrm{min})\end{array}$} & \multicolumn{2}{c}{ Coated with ZP } & & \multicolumn{2}{c}{ Not coated with ZP } \\
\cline { 2 - 3 } \cline { 5 - 6 } & \multicolumn{1}{c}{$\mathrm{H} 0$} & $\mathrm{H} 10$ & & $\mathrm{H} 0$ & $\mathrm{H} 10$ \\
\hline 15 & $3.9 \pm 0.6^{\mathrm{a}}$ & $3.5 \pm 1.8^{\mathrm{a}}$ & & $3.3 \pm 0.1^{\mathrm{a}}$ & $2.7 \pm 1.0 \mathrm{a}$ \\
30 & $18.8 \pm 0.6^{\mathrm{b}}$ & $12.8 \pm 4.1^{\mathrm{c}}$ & & $4.9 \pm 1.4^{\mathrm{a}}$ & $3.8 \pm 1.9^{\mathrm{a}}$ \\
60 & $30.8 \pm 2.2^{\mathrm{d}}$ & $17.4 \pm 4.5^{\mathrm{b}}$ & & $6.2 \pm 2.4^{\mathrm{a}}$ & $3.9 \pm 0.3^{\mathrm{a}}$ \\
\hline
\end{tabular}

Explanations: Sperm were counted by bright field microscopy $(\times 40)$. The total of sperm corresponds to 10 microscopic fields for each preparation. Each value represents the average of three replications of different individuals $(n=8) \pm$ SD. Different superscript letters $(\mathrm{a}, \mathrm{b}, \mathrm{c}, \mathrm{d})$ indicate significant differences $(\mathrm{P}<0.0001)$. H0: without heparin, H10: $10 \mu \mathrm{g} / \mathrm{ml}$ of heparin

In this work, we used indirect fluorescence microscopy to detect possible variations in the dynamics of heparin binding to sperm from boars with farrowing rates lower than 70\% (Group II). Two boars from this group showed decreased percentage of pattern B sperm upon capacitation, indicating a lower density of exposed heparin-binding sites in the acrosomal region. We hypothesised that this may probably be due to deficient dynamics on the redistribution of these sites. The difference, however, is not sufficient to affect the capacitation rate as determined by the induction of AR, indicating that the redistribution of heparinbinding sites may be a reflection of the early stages of the capacitation process, but is not essential for its progress. While more samples should be tested, this result indicates that an alteration of the redistribution of membrane compounds during capacitation may be responsible for the lower farrowing rates, at least of some animals with normal spermiogram parameters. The normal heparin-binding parameters of the other two animals of this group indicate that their low farrowing rate is due to causes different from abnormal membrane redistribution during capacitation. In our previous study (Dapino et al., 2009) we proposed that the change of heparin-binding pattern during capacitation may be due to the exposure of HBPs in the acrosomal region upon some spermadhesins shedding from the sperm surface at the beginning of the capacitation process, to the redistribution of anionic phospholipids from the acrosomal to the postacrosomal region, or to a combination of both. Töpfer-Petersen et al. (2008) have proposed a model in which some spermadhesins that interact with membrane phospholipids, such as AWN-1, DQH and AQN-3 (all belonging to the family of proteins that bind to heparin), remain bound to sperm after capacitation and may be involved in the union to ZP as primary acceptors (Van Gestel et al., 2007; Monásková et al., 2007). AQN-3 has been identified as a membrane-associated protein that is present in microdomains that emerge during in vitro capacitation at the apical ridge 
of the plasma membrane of the sperm head (Boerke et al., 2008). These spermadhesins, which are masked in non-capacitated sperm, are likely to emerge during capacitation and are responsible for the changes of the heparin-binding pattern. The exposure of HBPs during capacitation may have consequences in the subsequent steps of the fertilisation process, as is the binding of sperm to ZP. This is supported by a report that considers that certain HBPs are involved in sperm-ZP binding (Töpfer-Petersen et al., 2008).

Our results connecting altered heparin-binding site localisation during capacitation with low farrowing rates for some boars may reflect a direct consequence of the accessibility of heparin-binding sites or a more generalised unsuitable membrane redistribution. To further analyse the possible importance of heparin-binding site availability itself, we performed experiments to detect if the presence of heparin during capacitation of boar sperm in the proximity of ZP had any effect on sperm-ZP interaction. We found that in the absence of heparin, as capacitation proceeded, sperm binding to ZP increased. However, in the presence of heparin, binding was significantly lower than in its absence (Table 2). This result may be due to a competition between polysulphated groups from heparin and from ZP for sperm-binding sites (Tatemoto et al., 2005), supporting the importance of heparin-binding site availability in sperm for fertilisation.

During the periovulatory period in sows, only a restricted number of sperm is gradually released from oviductal reservoirs reaching the site of fertilisation in the ampulla, a fact which contributes to the existence of a 1:1 sperm/egg rate at the time of in vivo fertilisation, reducing the possibility of polyspermy (Suarez, 2008). Our findings show that heparin inhibits porcine sperm binding to ZP, probably competing for binding sites on the sperm head, in accordance with the previously reported role of HBP in the primary union of sperm to ZP (Van Gestel et al., 2007; Monásková et al., 2007). They also support a role for heparin in the pre-fertilisation prevention of polyspermy by a mechanism alternative to oviductal ZP modification, which has been reported by other authors (Coy et al., 2008).

Considering that heparin inhibits the primary binding of sperm to the zona pellucida in vitro (Table 2) and that sperm from two boars with normal semen quality parameters and low farrowing showed lower percentages of heparinbinding pattern B upon capacitation (Fig. 1), the redistribution of heparinbinding sites during capacitation may be considered a possible indicator of the presence of proteins involved in the process of fertilisation, specifically in the initial sperm-oocyte recognition. Further studies are needed; however, the detection of heparin-binding sites upon capacitation may become useful for the identification of a subpopulation of individuals with lower fertilising capacity. This may be particularly meaningful for high-production establishments that require individuals with the highest reproductive qualities. 


\section{Acknowledgement}

This work was supported by the ANPCyT-BID programme (grant number PICT 1284) of Argentina.

\section{References}

Bellin, M. E., Hawkins, H. E., Oyarzo, J. N., Vanderboom, R. J. and Ax, R. L. (1996): Monoclonal antibody detection of heparin-binding proteins on sperm corresponds to increased fertility of bulls. J. Anim. Sci. 74, 173-182.

Boerke, A., Tsai, P. S., Garcia-Gil, N., Brewis, I. A. and Gadella, B. M. (2008): Capacitationdependent reorganization of microdomains in the apical sperm head plasma membrane: functional relationship with zona binding and the zona-induced acrosome reaction. Theriogenology 70, 1188-1196.

Broekhuijse, M., Šoštarić, E., Feitsma, H. and Gadella, B. M. (2012): The value of microscopic semen motility assessment at collection for a commercial artificial insemination center, a retrospective study on factors explaining variation in pig fertility. Theriogenology 77, $1466-1479$.

Clark, L. K., Schinckel, A. P., Singleton, W. L., Einstein, M. E. and Teclaw, R. F. (1989): Use of farrowing rate as a measure of fertility of boars. J. Am. Vet. Med. Assoc. 194, 239-243.

Coy, P., Cánovas, S., Mondéjar, I., Saavedra, M. D., Romar, R., Grullón, L., Matás, C. and Avilés, M. (2008): Oviduct-specific glycoprotein and heparin modulate sperm-zona pellucida interaction during fertilization and contribute to control of polyspermy. Proc. Natl Acad. Sci. USA 105, 15809-15814.

Dapino, D. G., Teijeiro, J. M., Cabada, M. O. and Marini, P. E. (2009): Dynamics of heparinbinding proteins on boar sperm. Anim. Reprod. Sci. 116, 308-317.

Gadella, B., Tsai, P., Boerke, A. and Brewis, I. (2008): Sperm head membrane reorganization during capacitation. Int. J. Dev. Biol. 52, 473-480.

Hedrick, J. and Wardrip, N. (1986): Isolation of the zona pellucida and purification of its glycoprotein families from pig oocytes. Anal. Biochem. 157, 63-70.

Jonáková, V., Manásková, P. and Tichá, M. (2007): Separation, characterization and identification of boar seminal plasma protein. J. Chromatogr. B Analyt. Technol. Biomed. Life Sci. 849, $307-314$.

Leahy, T. and Gadella, B. M. (2011a): Capacitation and capacitation-like sperm surface changes induced by handling boar semen. Reprod. Domest. Anim. 2, 7-13.

Leahy, T. and Gadella, B. M. (2011b): Sperm surface changes and physiological consequences induced by sperm handling and storage. Reproduction 142, 759-778.

Lowry, O. H., Rosebrough, N. J., Farr, A. L. and Randall, R. J. (1951): Protein measurement with the Folin phenol reagent. J. Biol. Chem. 193, 265-275.

Monásková, P., Peknicová, J., Elzeinová, F., Tichá, M. and Jonáková, V. (2007): Origin, localization and binding abilities of boar DQH sperm surface protein tested by specific monoclonal antibodies. J. Reprod. Immunol. 74, 103-113.

Parrish, J., Susko-Parrish, J., Winer, M. and First, N. (1988): Capacitation of bovine sperm by heparin. Biol. Reprod. 38, 1171-1180.

Richardson, R. T., Nikolajczyk, B. S., Abdullah, L. H., Beavers, J. C. and O'Rand, M. G. (1991): Localization of rabbit sperm acrosin during the acrosome reaction induced by immobilized zona matrix. Biol. Reprod. 45, 20-26.

Rodríguez-Martínez, H., Kvist, U., Ernerudh, J., Sanz, L. and Calvete, J. J. (2011): Seminal plasma proteins: what role do they play? Am. J. Reprod. Immunol. 66, 11-22. 
Sanz, L., Calvete, J., Mann, K., Gabius, H. and Töpfer-Petersen, E. (1993): Isolation and biochemical characterization of heparin-binding proteins from boar seminal plasma: a dual role for spermadhesins in fertilization. Mol. Reprod. Dev. 35, 37-43.

Suarez, S. (2008): Regulation of sperm storage and movement in the mammalian oviduct. Int. J. Dev. Biol. 52, 455-462.

Tardif, S., Sirard, M., Sullivan, R. and Bailey, J. L. (1999): Identification of capacitation associated phosphoproteins in porcine sperm electroporated with ATP- $\gamma-{ }^{32} \mathrm{P}$. Mol. Reprod. Dev. 54, 292-302.

Tatemoto, H., Muto, N., Yim, S. D. and Nakada, T. (2005): Anti-hyaluronidase oligosaccharide derived from chondroitin sulphate A effectively reduces polyspermy during in vitro fertilization of porcine oocytes. Biol. Reprod. 72, 127-134.

Töpfer-Petersen, E., Ekhlasi-Hundrieser, M. and Tsolova, M. (2008): Glycobiology of fertilization in the pig. Int. J. Dev. Biol. 52, 717-736.

Van Gestel, R. A., Brewis, I. A., Ashton, P. R., Brouwers, J. F. and Gadella, B. M. (2007): Multiple proteins present in purified porcine sperm apical plasma membranes interact with the zona pellucida of the oocyte. Mol. Hum. Reprod. 13, 445-454.

Vázquez, J. M., Martínez, E., Martinez, P., Garcia-Artiga, C. and Roca, J. (1997): Hypoosmotic swelling of boar spermatozoa compared to other methods for analysing the sperm membrane. Theriogenology 47, 913-922.

Wells, M. E. and Awa, O. A. (1970): New technique for assessing acrosomal characteristics of spermatozoa. J. Dairy Sci. 53, 227-232. 